\title{
The Increased Levels of Faecal Calprotectin in Children With Active Enthesitis Related Arthritis and Mri Signs of Sacroiliitis: the Results of A Single Centre Cross-Sectional Study in Juvenile Idiopathic Arthritis Patients
}

Lovro Lamot ( $\sim$ lovro.lamot@gmail.com )

Klinicki bolnicki centar Sestre milosrdnice https://orcid.org/0000-0002-7939-115X

Marijana Miler

Sestre milosrdnice University Hospital Center

Rudolf Vukojevic

Sestre milosrdnice University Hospital Center

Mandica Vidovic

Sestre milosrdnice University Hospital Centre

Mirta Lamot

Sestre milosrdnice University Hospital Centre

Ivana Trutin

Sestre milosrdnice University Hospital Centre

Nora Nikolac Gabaj

Sestre milosrdnice University Hospital Centre

Miroslav Harjacek

Sestre milosrdnice University Hospital Centre, University of Zagreb School of Medicine

\section{Research article}

Keywords: juvenile idiopathic arthritis, enthesitis related arthritis, juvenile spondyloarthritis, faecal calprotectin, magnetic resonance imaging, sacroiliitis.

Posted Date: August 28th, 2020

DOI: https://doi.org/10.21203/rs.3.rs-66215/v1

License: (1) (i) This work is licensed under a Creative Commons Attribution 4.0 International License.

Read Full License 


\section{Abstract}

Background: Enthesitis related arthritis (ErA) is a specific subtype of juvenile idiopathic arthritis (JIA) which is often regarded as an undifferentiated form of juvenile spondyloarthritis (jSpA). Beside the arthritis of the peripheral joints, the crucial features of jSpA include enthesitis and/or arthritis of axial joints. Moreover, in adult onset spondyloarthritis gut is increasingly recognized as origin and/or target of inflammation, while the incidence of gut involvement in ErA patients is still largely unknown. The aim of this study was to assess the fCAL concentration, a surrogate marker of gut inflammation, in patients with various subtypes of JIA and non-inflammatory musculoskeletal conditions and to assess the correlation with various demographic, clinical, laboratory, imaging and treatment characteristics.

Methods: This was a cross-sectional study involving 71 patients with various forms of JIA and other noninflammatory musculoskeletal diseases (NI-MSD). Along with detailed clinical and laboratory examination, fCAL and magnetic resonance imaging (MRI) of sacroiliac joints, thoracic and lumbar spine was routinely performed in all ErA patients, as well as in other patients who complained of abdominal and/or back pain, respectively. In all JIA patients, disease activity was measured using the juvenile arthritis (JADAS) or spondyloarthritis (jSpADA) disease activity score.

Results: The median concentration of fCAL was highest in ErA subgroup ( $33.2 \mathrm{mg} / \mathrm{kg}, \mathrm{p}=0.043$ ), with a significant difference between patients with inactive and active disease $(20.0 \mathrm{mg} / \mathrm{kg} \mathrm{vs} 57.4 \mathrm{mg} / \mathrm{kg}$, $\mathrm{p}=0.01)$, as well as between those with or without MRI signs of SIJ inflammation $(22.6 \mathrm{mg} / \mathrm{kg}$ vs 54.3 $\mathrm{mg} / \mathrm{kg}, \mathrm{p}=0.048)$. In all patients, the fCAL concentration did not significantly differ among those receiving and not receiving NSAIDs ( $23 \mathrm{mg} / \mathrm{kg}$ vs $20 \mathrm{mg} / \mathrm{kg}, \mathrm{p}=0.18$ ), although weak correlation was found with the duration of the use $(r=0.25, p=0.03)$.

Conclusion: The (subclinical) gut inflammation might not be present only in adults with SpA, but also in children with undifferentiated forms of the jSpA, especially with active disease and/or MRI signs of SI inflammation.

\section{Background}

Joint pain and/or swelling with limited range of motion is a common manifestation of many paediatric diseases, most notably wide range of rheumatic conditions. If both of these symptoms are present for longer than 6 weeks in a patient younger than 16 years of age, the diagnosis of juvenile idiopathic arthritis (JIA), the most common childhood rheumatic disease, should be considered (1). Nevertheless, JIA is far from being the only cause of the arthritis in children. Beside non-inflammatory musculoskeletal conditions, joint involvement is the most common extraintestinal manifestation in children with inflammatory bowel disease (IBD) and may involve $16-33 \%$ of patients at the time of diagnosis or during the follow-up (2). Conversely, gastrointestinal (GI) symptoms are present in the majority of JIA patients, while up to $85 \%$ of JIA patients with significant GI symptoms have histological evidence of mild nonspecific inflammation $(3,4)$. Although it has been reported that JIA patient might experience 
abdominal pain related to NSAID use, the data from the German biologics registry (BiKeR) have shown that IBD incidence in patients with JIA is higher than the incidence in pediatric population $(5,6)$. Interestingly, the IBD incidence was significantly lower in patients treated with MTX, while etanercept monotherapy was associated with increased incidence of IBD (6).

Among different subtypes of JIA, gut inflammation is most commonly associated with enthesitis related arthritis (ErA), which is along the seronegative enthesopathy and arthropathy syndrome often regarded as an undifferentiated form of juvenile spondyloarthritis (jSpA) (7). However, jSpA encompasses differentiated forms such as juvenile ankylosing spondylitis (jAS), psoriatic arthritis (PsA), reactive arthritis (ReA) and arthritis associated with IBD, as well (7). Beside the arthritis of the peripheral joints, the crucial features of jSpA include enthesitis and/or arthritis of axial joints. Although there are some differences between SpA in children and adults, mostly in tendency to involve axial joints which is more remarkable in adults, there are emerging views that spondyloarthritis (SpA) surpasses this arbitrary agebased divide (8). Nevertheless, it is still unclear if the clinically silent macroscopic and microscopic gut inflammation which occurs in about $60 \%$ of adult patient with ankylosing spondylitis (AS) is present in children with jSpA as well (9). This might be due to the challenges imposed by the use of endoscopy, the gold standard for detailed assessment of the inflammation in the gut, which are especially prominent in children (10). Since this procedure is invasive, has to be performed under general anesthesia, and has a potential for rare procedural accidents, such as bleeding and perforation, many children and their parents experience discomfort, anxiety and dissatisfaction $(11,12)$. Besides, symptoms of IBD, such as abdominal pain and diarrhea, are rather vague, particularly in children, and overlap with symptoms of functional gastrointestinal disorders, which makes distinguishing those two rather challenging (13). Therefore, non-invasive tests such as blood and faecal biomarkers are increasingly used in clinical practice to help select patients who might benefit from endoscopies.

In recent years, faecal calprotectin ( $\mathrm{fCAL}$ ), a member of the $\mathrm{S} 100$ calcium-binding protein family expressed in phagocytes, monocytes, macrophages and granulocytes, has emerged as a valuable screening tool for the gut inflammation, both in adults and children (14). Since it is released from activated monocytes and granulocytes at local sites of inflammation (eg, intestinal mucosa in IBD) during the early phase of the immune response, and since it has a noticeable extracellular proinflammatory effects via toll-like receptor 4 dependent mechanism, it has been regarded as a marker of innate immune activation (15). Although many studies have shown increased fCAL in adult SpA patients, there has been only few studies of fCAL levels in jSpA and JIA (16-20). Moreover, to best of our knowledge, no study has investigated the relationship of fCAL concentration in children with JIA and the disease activity indices and features such as signs of sacroiliitis, treatment modalities and demographic data such as gender, disease onset and duration, which have all been associated with microscopic gut inflammation in adult SpA patients (21-26).

The aim of this study was therefore to assess the fCAL concentration in patients with various subtypes of JIA and non-inflammatory musculoskeletal conditions and to assess the correlation with various demographic, clinical, laboratory, imaging and treatment characteristics. 


\section{Methods}

\section{Patients}

This was a cross-sectional study performed during the year 2019. In total, 71 patients followed at the Division of Clinical Immunology and Rheumatology at the Department of Pedaitrics in Sestre milosrdnice University Hospital center, Zagreb, Croatia, a tertiary care hospital, were assessed for fCAL. Patients who were diagnosed with ErA or PsA were routinely assessed regardless of the GI symptoms, while patients with other forms of JIA (oligo and polyarticular), as well as patients with non-inflammatory musculoskeletal diseases (NI-MSD) were assessed if they complained of abdominal pain. Along with fCAL assessment, a detailed clinical and laboratory examination was performed for each patient, including the calculation of a juvenile arthritis disease activity score (JADAS) for those diagnosed with oligo and polyarticular JIA, and juvenile spondyloarthritis disease activity (jSpADA) for those diagnosed with $\operatorname{ErA}(27,28)$. Moreover, as a part of a standard diagnostic procedure, in all ErA patients, as well as in other patients who complained of an inflammatory low back pain, MRI of the sacroiliac joints (SIJ) along with MRI of thoracic and lumbar spine was performed and analysed by experienced musculoskeletal radiologist according to consensus definitions of components of the Juvenile Arthritis Magnetic Resonance Image Sacroiliac Joint Scoring System (JAMRIS-SIJ) $(29,30)$. In all ErA and oligo and polyarticular JIA patients, as well as in some NI-MSD patients, the antinuclear antibodies (ANA) and rheumatoid factor (RF) was determined. Moreover, in all ErA patients, as well as in some oligo and polyarticular JIA and NI-MSD patients, the presence of HLA-B27 antigen was determined. The diagnosis of JIA was made in accordance with the criteria of International League of Associations for Rheumatology (ILAR), while the diagnosis of NI-MSD was made in patients who had no signs of systemic or local inflammation (31). The disease in ErA and JIA patients was regarded as inactive if jSpADA or JADAS, respectively, were $\leq 1$. The detailed patient's characteristics are shown in Table 1. 
Table 1

Demographic data, disease characteristics, laboratory and MRI findings, treatment modalities and fCAL concentrations in study participants.

\begin{tabular}{|c|c|c|c|c|}
\hline & ErA & PsA & JIA & $\begin{array}{l}\mathrm{NI-} \\
\text { MSD }\end{array}$ \\
\hline $\mathbf{N}$ (\% female) & $\begin{array}{l}26 \\
(65 \%)\end{array}$ & $4(100 \%)$ & $\begin{array}{l}29 \\
(57 \%)\end{array}$ & $\begin{array}{l}12 \\
(67 \%)\end{array}$ \\
\hline \multirow[t]{2}{*}{ Age (median years, IQR) } & 12 & 10.8 & 11 & 13 \\
\hline & $\begin{array}{l}(7.7- \\
14.5)\end{array}$ & $(8-13.9)$ & $(7-14)$ & $\begin{array}{l}(6.1- \\
14)\end{array}$ \\
\hline \multirow[t]{2}{*}{ Disease duration (median months IQR) } & 21 & 15 & 18 & 9 \\
\hline & $\begin{array}{l}(6- \\
54)\end{array}$ & $\begin{array}{l}(1.2- \\
50.4)\end{array}$ & $(6-74.4)$ & $\begin{array}{l}(0- \\
12)\end{array}$ \\
\hline \multirow[t]{2}{*}{ Active joints (median N, IQR) } & 0 & 1 & 0 & 0 \\
\hline & $(0-2)$ & $(0-9.5)$ & $(0-3.5)$ & \\
\hline \multirow[t]{2}{*}{ Active enthesis (median N, IQR) } & 1 & 1 & 0 & 0 \\
\hline & $(0-2)$ & $(0-2.7)$ & & \\
\hline \multirow[t]{2}{*}{ Pain (median VAS, IQR) ${ }^{7}$} & 3 & 2.5 & 0 & 0 \\
\hline & $(0-5)$ & $(0.5-3)$ & $(0-3.5)$ & $(0-3.7)$ \\
\hline \multirow{2}{*}{$\begin{array}{l}\text { Patient/parent's global assessment of a child's overall } \\
\text { well-being (median VAS, IQR) }\end{array}$} & 2.5 & 1.25 & 1.5 & 0 \\
\hline & 4) & $1.5)$ & $(0-2.5)$ & $(0-3.7)$ \\
\hline \multirow{2}{*}{$\begin{array}{l}\text { Physician global assessment of disease activity (median } \\
\text { VAS, IQR) }\end{array}$} & 1.5 & 0.75 & 1 & 0 \\
\hline & $\begin{array}{l}(0.37- \\
3)\end{array}$ & $(0.12-1)$ & $(0-2)$ & $\begin{array}{l}(0- \\
1.75)\end{array}$ \\
\hline Morning stiffens ${ }^{1}(\mathrm{~N})$ & 6 & 0 & 7 & 0 \\
\hline Clinical sacroiliitis ${ }^{2}(\mathrm{~N})$ & 5 & 0 & 0 & 0 \\
\hline Abnormal back mobility ${ }^{3}(\mathrm{~N})$ & 4 & 0 & 0 & 0 \\
\hline Uveitis $^{4}(\mathrm{~N})$ & 1 & 0 & 1 & 1 \\
\hline Positive family history ${ }^{5}(\mathrm{~N})$ & 13 & 3 & 11 & 3 \\
\hline Gastrointestinal symptoms ${ }^{6}(\mathrm{~N})$ & 5 & 0 & 29 & 12 \\
\hline \multicolumn{5}{|l|}{ Laboratory findings } \\
\hline HLA-B27* ( $\mathrm{N}$ of positive / $\mathrm{N}$ analyzed) & $12 / 26$ & $1 / 4$ & $0 / 13$ & $0 / 2$ \\
\hline
\end{tabular}




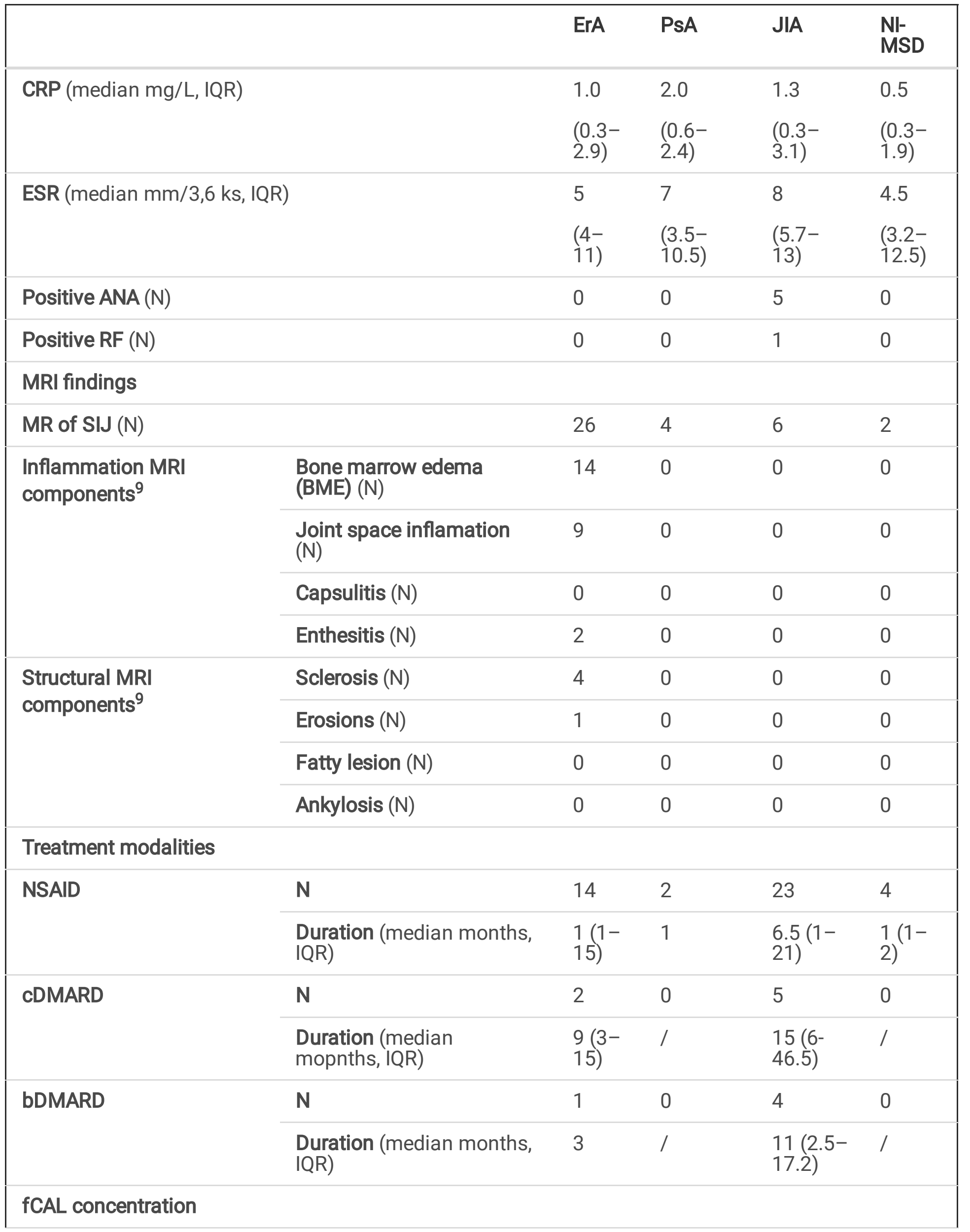




\begin{tabular}{|l|llll|}
\hline & ErA & PsA & JIA & NI- \\
MSD
\end{tabular}

Due to a very different presentation and evolution from other JIA subtypes, systemic JIA was excluded, which also allowed comparing with other studies.

Concentration of $\mathrm{C}$ reactive protein (CRP) and RF were measured by immunoturbidimetric method on Architect c8000 (Abbott, Abbott Park, IL, USA) with the original manufacturers' reagents. ANA titre was determined by indirect immunofluorescence on human epithelial (HEp-2) cells (Euroimmun, Lübeck, Germany). Positive values for RF and ANA were considered above $30 \mathrm{IU} / \mathrm{mL}$ and titre 1:100, respectively. Fecal calprotectin (fCAL) 
Fecal calprotectin was measured by PETIA (particle enhanced turbidimetric immunoassay) on automatic biochemistry analyzer Architect c8000 (Abbott Laboratories, Illinois, USA) using BühImann fCAL $®$ turbo assay (BÜHLMANN Laboratories AG, Schönenbuch, Switzerland). Fecal samples were extracted with extraction buffer using the CALEX® Cap extraction device. The extracts were incubated with reaction buffer and mixed with polystyrene nanoparticles coated with calprotectin-specific antibodies. Calprotectin from the sample mediated the immunoparticle agglutination. Sample turbidity caused by calprotectinimmunoparticle complex formation was proportional to calprotectin concentration. The lower and upper limits of the detection were 20 to $8000 \mathrm{mg} / \mathrm{kg}$, respectively. According to the manufacturer's instructions, the fCAL levels below $50 \mathrm{mg} / \mathrm{kg}$ were considered normal, those between 50 and $200 \mathrm{mg} / \mathrm{kg}$ as slightly elevated, and those above $200 \mathrm{mg} / \mathrm{kg}$ as elevated, both in adults and children between 4-17 years (32).

\section{Statistical analysis}

Data were analysed using GraphPad Prism 8 and $p<0.05$ was considered statistically significant. Normality of distribution was tested with Saphiro-Wilk test and data are presented as interquartile ranges (IQR) and medians. Statistical comparisons between two groups were performed using the Student's ttest (normal distribution) or the Mann-Whitney $U$ test, while the comparisons between three or more groups were performed by Kruskall-Wallis test. Correlations between the parameters were calculated using the Spearman rank correlation. For the calprotectin test, the results below the detection limits were equalized to $20 \mathrm{mg} / \mathrm{kg}$.

\section{Results}

\section{Faecal calprotectin in patients with various forms of JIA}

Among 71 patients, 26 were diagnosed with ErA, 4 with PsA, 29 with oligo and/or polyrticular JIA and 12 with NI-MSD (Table 1). The median concentration of fCAL was highest in ErA subgroup (33.2 [20-84.8], $\mathrm{p}=0.043$ ) (Figure 1a). Moreover, $3 / 26$ patients in ErA subgroup had fCAL concentrations above $200 \mathrm{mg} / \mathrm{kg}$, while $5 / 26$ had the concentration in $50-200 \mathrm{mg} / \mathrm{kg}$ range. In PsA patients the median fCAL value was 20 (20-30.7) with the fCAL concentrations below $50 \mathrm{mg} / \mathrm{kg}$ in all four patients. In patients with oligo and/or polyarticular type of JIA, 1/29 had a fCAL level above $200 \mathrm{mg} / \mathrm{kg}$, while 4/29 had the concentration in $50-200 \mathrm{mg} / \mathrm{kg}$ range. Finally, only $2 / 12 \mathrm{NI}-\mathrm{MSD}$ patients had the concentration of fCAL in the range of $50-200 \mathrm{mg} / \mathrm{kg}$, while none of the 12 patients had a concentration above. No significant correlation was observed between $\mathrm{fCAL}$ concentration and age at the time of sampling, duration of the disease, number of active joints and/or enthesis, physician global assessment, CRP or ESR concentrations, and disease activity in JIA patients measured by JADAS (data not shown). There was no difference between the fCAL values in patients with inactive (JADAS $\leq 1$ ) or active (JADAS $\geq 1$ ) disease ( $20.0 \mathrm{mg} / \mathrm{kg}$ vs $20.0 \mathrm{mg} / \mathrm{kg}, \mathrm{p}=0.934)$.

\section{Faecal calprotectin in patients with ErA}

In patients with ErA, moderate correlation was observed between $\mathrm{fCAL}$ concentration and the disease activity measured by jSpADA $(r=0.46, p=0.02)$. Besides, there was a significant difference in $\mathrm{fCAL}$ 
concentration between ErA patients with inactive (jSpADA $\leq 1)$ or active (jSpADA $\geq 1)$ disease (20.0 $\mathrm{mg} / \mathrm{kg}$ vs $57.4 \mathrm{mg} / \mathrm{kg}, \mathrm{p}=0.01)$. Moreover, ErA patients with one or more sign of SI inflammation on MRI had a significantly higher fCAL concentrations than those without the signs of inflammation $(22.6 \mathrm{mg} / \mathrm{kg}$ vs $54.3 \mathrm{mg} / \mathrm{kg}, \mathrm{p}=0.048)$. Among all patients with ErA, the median levels of fCAL were highest in those with active disease (jSpADA $\geq 1)$ and MRI sign(s) of sacroiliitis $(77.7[26-226.1] \mathrm{mg} / \mathrm{kg}, \mathrm{p}=0.043$ ) (Figure $1 \mathrm{~b})$, with three patients who had fCAL concentration above $200 \mathrm{mg} / \mathrm{kg}$, and three in $50-200 \mathrm{mg} / \mathrm{kg}$ range. In JIA subgroup, the median fCAL levels were 20 (20-31.5) $\mathrm{mg} / \mathrm{kg}$, with one patient's concentration above $200 \mathrm{mg} / \mathrm{kg}$ and four in the $50-200 \mathrm{mg} / \mathrm{kg}$ range.

\section{Faecal calprotectin and various treatment modalities}

Of 71 patients, $43(60.5 \%)$ were treated with NSAIDs at the time of sampling for the average time of 1 (117) months. The majority of those patients came from the oligo and polyarticular JIA subgroup, where 23 of 29 patients were receiving NSAIDs for the median time of 6.5 (1-21) months, followed by patients with ErA where 14 out of 26 were receiving NSAIDs for 1 (1-15) months, PsA where 2 out of 4 patients were treated with NSADs for 1 month and NI-MSD where 4 out of 12 were treated for a median time of 1 (1-2) months before the fCAL sampling. The number of patients receiving conventional disease modifying antirheumatic drugs (CDMARD) was 7, with a median duration of $15(5-21) ; 2$ of them were in ErA subgroup (median duration 9 [3-15] months) and 5 in oligo and polyarticular JIA subgroup (median duration 15 [6-46.5] months). Biological disease modifying antirheumatic drugs (bDMARD) were used in four patients with oligo and polyarticular JIA only, for a median time of 11 (2.5-17.2) months and in one patient with ErA for three months. Finally, three patients were treated with glucocorticoids (GC) at the time of sampling for the median time of 12 (2-27) months. Of those patients, 2 had oligo and polyarticular JIA (median duration of treatment 19.5 [12-27]) and 1 had ErA (duration of treatment 2 months).

In all patients, the fCAL concentration did not significantly differ among those receiving and not receiving NSAIDs (the median value was 23 [20-49.6] mg/ $\mathrm{kg}$ in patients receiving NSAIDS vs 20 [20-33.6] mg/kg in patients not receiving NSAIDs, $p=0.18$ ), although weak correlation was found with the duration of the use $(r=0.25, p=0.03)$. No correlation was observed between fCAL levels and other treatment modalities and duration. The median value of the fCAL concentration in patients receiving DMARDs was 32.6 (20-44.4) $\mathrm{mg} / \mathrm{kg}$, higher than in patients not receiving these medications in which the median value was $20 \mathrm{mg} / \mathrm{kg}$ $(20-46.7, p=0.27)$. Moreover, the median value of $f C A L$ in patients receiving bDMARDs was $26.3 \mathrm{mg} / \mathrm{kg}$ (20-51.6), while in those who were not receiving bDMARDs, the median value was $20 \mathrm{mg} / \mathrm{kg}$ (20-46.7, $p=0.95)$. Comparing the patients who were receiving and who were not receiving $G C s$, the fCAL median value was the same, $20 \mathrm{mg} / \mathrm{kg}$ (20-39.4 vs 20-46.7 respectively, $p=0.66)$. Finally, patients receiving medications (NSAIDs, DMARDs, GCs) and patients not receiving any medications had the same median fCAL values of $20 \mathrm{mg} / \mathrm{kg}$ (20-46.3 vs 20-46.1 respectively, $\mathrm{p}=0.64)$.

\section{Faecal calprotectin and endoscopic evaluation}

In one ErA patient with the highest fCAL concentration ( $838.8 \mathrm{mg} / \mathrm{kg}$ ) the upper $\mathrm{Gl}$ endoscopy and ileocolonoscopy was performed after the exclusion of bacterial GI tract infections, with no macroscopic and 
microscopic findings characteristic for IBD and/or coeliac disease. Nevertheless, on several biopsies taken from colon, caecum, ileocecal valve and terminal ileum, lymphoid infiltration in the lamina propria was described, while the stomach biopsies showed the monocyte infiltration in the lamina propria, with the signs of Helicobacter pylori negative chronic gastritis. Interestingly, the fCAL levels on repeated measuring after six months were $27.6 \mathrm{mg} / \mathrm{kg}$.

\section{Discussion}

The association of epithelial barrier and joint inflammation has become an intense area of both basic and clinical research, with the immediate challenge to understand the immunopathogenic link and the diagnostic utility in the relation to both IBD and SpA (33). Beside the better understanding of mechanisms underlying those diseases, the potential benefit of this efforts might arise from the discovery of the future treatment strategies. Although there is no consistent confirmation for the genetical, immunological and environmental ties between gut and joints, there are several clinical indications suggesting a close link between IBD and SpA in adults, while the results of our study will help to further establish this link in children (34).

In our study, we have shown that among patients with various subtypes of JIA, the fCAL concentrations were highest in those with ErA subtype, which is alongside similar studies in adult SpA patients and two studies in children (16-20). Interestingly, almost a third of patients with this particular type of JIA had fCAL concentrations above the range regarded as normal $(50 \mathrm{mg} / \mathrm{kg})$. The novel finding of our study was that fCAL concentrations were significantly higher in ErA patients with any of the MRI sign characteristic for the SIJ inflammation according to consensus definitions of components of the JAMRIS-SIJ (30). This finding adds to the growing number of evidences for a clinical association of gut inflammation and axial spondyloarthritis in adult patients (34-37). Rheumatology based studies are reporting that $5-10 \%$ of patients with ankylosing spondylitis, a subtype of SpA with the most prominent axial inflammation, have IBD, while almost $50 \%$ of patients have subclinical gut inflammation (34). Similarly, gastroenterologybased studies provide a complementary view. A 20 years long prospective study of 599 patients with IBD have shown that $45 \%$ of patients is reporting a chronic back pain (35). In these studies, chronicity of IBD was significantly associated with comorbid axial SpA compared with patients without back complaints. Interestingly, another study has shown that erosive changes in the sacroiliac joints, defined by computer tomography (CT) scans, were twice as frequent in IBD patients than in controls (36). Furthermore, a recent retrospective study in a group of 34 children with IBD who underwent magnetic resonance enterography (MRE) for gastrointestinal disease evaluation have shown that five had radiological signs of SI inflammation at MRE, although no patient complained of musculoskeletal symptoms, nor had pathological findings at articular examination (37). This is somewhat in line with the observation that MRI is more sensitive in the assessment of inflammatory and destructive changes in JIA and jSpA than physical examination, radiographs or ultrasound (38). With this in mind, our study for the first time gives some clue that the concomitant inflammation of the gut and sacroiliac joints can be present early in the course of SpA. Moreover, to best of our knowledge, our study was the first to correlate the fCAL concentrations with somewhat novel disease activity scores, such as JADAS and jSpADA $(27,28)$. The 
final version of the JSPADA consists of eight items which reflect the status of uveitis, peripheral and axial disease, but as might be expected, none of the items involves the GI status (28). Nevertheless, we have shown that patients with active disease measured by jSpADA have significantly higher levels of fCAL, which might indicate that gastrointestinal inflammation revealed by fCAL measurement is a part of a wider inflammatory process present in patients with ErA. Therefore, it didn't come as a surprise that the highest levels of fCAL noted in our study were observed in ErA patients with active disease and MRI signs of sacroiliitis. Taking all this into consideration, the results of our study support the wider diagnostic approach to ErA patients, which involves measuring of fCAL especially in patients with active disease and/or MRI signs of sacroiliitis, even without the signs of GI involvement, and vice versa, performing a MRI of SIJ in ErA patients with increased levels of fCAL and active disease, even without the signs of lower back pain.

As opposite to some previous studies, the fCAL levels in our study were not associated with the use of NSAIDs, as well as with the use of other treatment modalities for JIA (20). It has been shown that NSAID use in adults may result in the intestinal inflammation and an increase in fCAL levels, while the drug discontinuation results in the decline of the FC levels, suggesting healing of the gut mucosa (39). Since we performed a cross sectional study with the focus on real-life data, the treatment modalities were not adjusted before the fCAL was measured. Regardless, the fCAL levels were highest in ErA subgroup in which less proportion of patients (14/26) was treated with NSAIDs than in oligo and polyarticular JIA subgroup (23/29), suggesting the fCAL levels might be even higher in ErA patients if NSAIDs were discontinued before the measurement.

There are several important limitations to our study. Although the best available evidence in the literature supports the use of FCAL in IBD diagnosis and monitoring, as well as in distinguishing between IBD and IBS, the gold standard for the detection of (sub)clinical gut inflammation remains the endoscopy and biopsy, which was in our study performed only in one patient $(40,41)$. Moreover, we didn't report on repeated values of the fCAL measurement. Nevertheless, this might be of lesser importance, since the primary aim of our study was to assess the presence of the gut inflammation in patients with various forms of JIA via the use of surrogate non-invasive biomarker in a prospective cohort of consecutive patients followed at a single paediatric rheumatology centre, regardless of their clinical characteristics, disease status and/or concomitant therapy.

In conclusion, the results of our study show that patients with enthesitis related arthritis, have significantly higher fCAL levels than those with other form of JIA or non-inflammatory musculoskeletal disorders. Moreover, the levels were the highest in ErA patients with active disease and the MRI sign(s) of the inflammatory process in sacroiliac joints, which emphasizes that a parallel inflammation in musculoskeletal system and gut can occur not just in adults with SpA, but also in children with undifferentiated SpA. Although this observation still needs to be confirmed in a prospective study involving larger number of patients, it should already be considered in everyday clinical practice when planning diagnostic procedures and treatment modalities for ErA patients. 


\section{List Of Abbreviations}

ANA: antinuclear antibodies;

AS: ankylosing spondylitis;

bDMARD: Biological disease modifying antirheumatic drugs;

CDMARD: conventional disease modifying antirheumatic drugs;

CRP: $\mathrm{C}$ reactive protein;

ErA: enthesitis related arthritis;

fCAL: faecal calprotectin;

Gl: gastrointestinal;

GS: glucocorticoids;

IBD: inflammatory bowel disease;

ILAR: International League of Associations for Rheumatology;

JADAS: juvenile arthritis disease activity score;

JAMARIS - SIJ: Juvenile Arthritis Magnetic Resonance Image Sacroiliac Joint Scoring System;

jAS: juvenile ankylosing spondylitis;

JIA: juvenile idiopathic arthritis;

jSpA: juvenile spondyloarthritis;

jSpADA: juvenile spondyloarthritis disease activity;

MRI: magnetic resonance imaging;

NI-MSD: non-inflammatory musculoskeletal diseases;

NI-MSD: non-inflammatory musculoskeletal diseases;

NSAID: nonsteroid anti-inflammatory drug;

PsA: psoriatic arthritis;

ReA: reactive arthritis; 
RF: rheumatoid factor;

SIJ: sacroiliac joints;

SpA: spondyloarthritis;

\section{Declarations}

\section{Ethics approval and consent to participate:}

This study is a retrospective chart review. Original data collection and consenting procedures were approved by the ethical committee of Sestre milosrdnice University Hospital Center. Laboratory tests and/or diagnostic procedures were performed according to the good clinical practice, and no extra samples and/or diagnostic procedures were performed for study purposes.

\section{Consent for publication:}

Not applicable.

\section{Availability of data and materials:}

All data generated or analysed during this study are included in this published article.

\section{Competing interests:}

The authors declare that they have no competing interests.

\section{Funding:}

There were no extra funding relating to this study.

\section{Authors' contributions:}

LL: study design, charts review, data interpretation, statistical analysis, manuscript preparation; MM: data interpretation, statistical analysis, final review of the manuscript; RV: data interpretation, final review of the manuscript; MV: data interpretation, final review of the manuscript; ML: charts review, manuscript preparation; NNG: laboratory analysis, statistical analysis, final review of the manuscript; $\mathrm{MH}$ : study design, data interpretation, final review of the manuscript.

\section{Acknowledgements:}

The authors gratefully acknowledge excellent assistance with the charts review by Ana Kovacevic, MD, from the Department of Pediatrics in Sestre milosrdnice University Hospital Center, Zagreb, Croatia.

\section{References}


1. Prakken B, Albani S, Martini A. Juvenile idiopathic arthritis. Lancet. 2011;377(9783):2138-49.

2. Cardile $S$, Romano $C$. Current issues in pediatric inflammatory bowel disease-associated arthropathies. World J Gastroenterol. 2014;20(1):45-52.

3. Brunner HI, Johnson AL, Barron AC, Passo MH, Griffin TA, Graham TB, et al. Gastrointestinal symptoms and their association with health-related quality of life of children with juvenile rheumatoid arthritis: validation of a gastrointestinal symptom questionnaire. J Clin Rheumatol. 2005;11(4):194-204.

4. Pichler J, Ong C, Shah N, Sebire N, Kiparrissi F, Borrelli O, et al. Histopathological features of gastrointestinal mucosal biopsies in children with juvenile idiopathic arthritis. Pediatr Res. 2016;79(6):895-901.

5. Ashorn $M$, Verronen P, Ruuska T, Huhtala $H$. Upper endoscopic findings in children with active juvenile chronic arthritis. Acta Paediatr. 2003;92(5):558-61.

6. Barthel D, Ganser G, Kuester RM, Onken N, Minden K, Girschick HJ, et al. Inflammatory Bowel Disease in Juvenile Idiopathic Arthritis Patients Treated with Biologics. J Rheumatol. 2015;42(11):2160-5.

7. Tse SM, Laxer RM. New advances in juvenile spondyloarthritis. Nat Rev Rheumatol. 2012;8(5):26979.

8. Nigrovic PA, Raychaudhuri S, Thompson SD. Review: Genetics and the Classification of Arthritis in Adults and Children. Arthritis Rheumatol. 2018;70(1):7-17.

9. Fragoulis GE, Liava C, Daoussis D, Akriviadis E, Garyfallos A, Dimitroulas T. Inflammatory bowel diseases and spondyloarthropathies: From pathogenesis to treatment. World J Gastroenterol. 2019;25(18):2162-76.

10. Levine A, Koletzko S, Turner D, Escher JC, Cucchiara S, de Ridder L, et al. ESPGHAN revised porto criteria for the diagnosis of inflammatory bowel disease in children and adolescents. J Pediatr Gastroenterol Nutr. 2014;58(6):795-806.

11. Hagiwara S, Nakayama Y, Tagawa M, Arai K, Ishige T, Murakoshi T, et al. Pediatric Patient and Parental Anxiety and Impressions Related to Initial Gastrointestinal Endoscopy: A Japanese Multicenter Questionnaire Study. Scientifica (Cairo). 2015;2015:797564.

12. Drossman DA, Brandt LJ, Sears C, Li Z, Nat J, Bozymski EM. A preliminary study of patients' concerns related to GI endoscopy. Am J Gastroenterol. 1996;91(2):287-91.

13. Akobeng AK. Clinical usefulness of the faecal calprotectin test in suspected paediatric inflammatory bowel disease. Acta Paediatr. 2018;107(11):2019-23.

14. Brookes MJ, Whitehead S, Gaya DR, Hawthorne AB. Practical guidance on the use of faecal calprotectin. Frontline Gastroenterol. 2018;9(2):87-91.

15. Vogl T, Tenbrock K, Ludwig S, Leukert N, Ehrhardt C, van Zoelen MA, et al. Mrp8 and Mrp14 are endogenous activators of Toll-like receptor 4, promoting lethal, endotoxin-induced shock. Nat Med. 2007;13(9):1042-9. 
16. Cypers H, Varkas G, Beeckman S, Debusschere K, Vogl T, Roth J, et al. Elevated calprotectin levels reveal bowel inflammation in spondyloarthritis. Ann Rheum Dis. 2016;75(7):1357-62.

17. Ostgard RD, Deleuran BW, Dam MY, Hansen IT, Jurik AG, Glerup H. Faecal calprotectin detects subclinical bowel inflammation and may predict treatment response in spondyloarthritis. Scand $J$ Rheumatol. 2018;47(1):48-55.

18. Klingberg E, Carlsten H, Hilme E, Hedberg M, Forsblad-d'Elia H. Calprotectin in ankylosing spondylitis-frequently elevated in feces, but normal in serum. Scand J Gastroenterol. 2012;47(4):435-44.

19. Stoll ML, Punaro M, Patel AS. Fecal calprotectin in children with the enthesitis-related arthritis subtype of juvenile idiopathic arthritis. J Rheumatol. 2011;38(10):2274-5.

20. Aalto K, Lahdenne P, Kolho KL. Fecal calprotectin in juvenile idiopathic arthritis patients related to drug use. Pediatr Rheumatol Online J. 2017;15(1):9.

21. Essers I, Ramiro S, Stolwijk C, Blaauw M, Landewe R, van der Heijde D, et al. Characteristics associated with the presence and development of extra-articular manifestations in ankylosing spondylitis: 12-year results from OASIS. Rheumatology (Oxford). 2015;54(4):633-40.

22. Dougados M, d'Agostino MA, Benessiano J, Berenbaum F, Breban M, Claudepierre P, et al. The DESIR cohort: a 10-year follow-up of early inflammatory back pain in France: study design and baseline characteristics of the 708 recruited patients. Joint Bone Spine. 2011;78(6):598-603.

23. Rudwaleit M, Haibel H, Baraliakos X, Listing J, Marker-Hermann E, Zeidler H, et al. The early disease stage in axial spondylarthritis: results from the German Spondyloarthritis Inception Cohort. Arthritis Rheum. 2009;60(3):717-27.

24. Cantini F, Niccoli L, Nannini C, Cassara E, Kaloudi O, Rizzello F, et al. Case-control Study on Dactylitis, Enthesitis, and Anterior Uveitis in Spondyloarthritis Associated with Inflammatory Bowel Diseases: Role of Coexistent Psoriasis. J Rheumatol. 2017;44(9):1341-6.

25. Van Praet L, Jans L, Carron P, Jacques P, Glorieus E, Colman R, et al. Degree of bone marrow oedema in sacroiliac joints of patients with axial spondyloarthritis is linked to gut inflammation and male sex: results from the GIANT cohort. Ann Rheum Dis. 2014;73(6):1186-9.

26. Van Praet L, Van den Bosch FE, Jacques P, Carron P, Jans L, Colman R, et al. Microscopic gut inflammation in axial spondyloarthritis: a multiparametric predictive model. Ann Rheum Dis. 2013;72(3):414-7.

27. Consolaro A, Ruperto N, Bazso A, Pistorio A, Magni-Manzoni S, Filocamo G, et al. Development and validation of a composite disease activity score for juvenile idiopathic arthritis. Arthritis Rheum. 2009;61(5):658-66.

28. Weiss PF, Colbert RA, Xiao R, Feudtner C, Beukelman T, DeWitt EM, et al. Development and retrospective validation of the juvenile spondyloarthritis disease activity index. Arthritis Care Res (Hoboken). 2014;66(12):1775-82.

29. Herregods N, Dehoorne J, Van den Bosch F, Jaremko JL, Van Vlaenderen J, Joos R, et al. ASAS definition for sacroiliitis on MRI in SpA: applicable to children? Pediatr Rheumatol Online J. $2017 ; 15(1): 24$. 
30. Otobo TM, Conaghan PG, Maksymowych WP, van der Heijde D, Weiss P, Sudol-Szopinska I, et al. Preliminary Definitions for Sacroiliac Joint Pathologies in the OMERACT Juvenile Idiopathic Arthritis Magnetic Resonance Imaging Score (OMERACT JAMRIS-SIJ). J Rheumatol. 2019;46(9):1192-7.

31. Petty RE, Southwood TR, Manners P, Baum J, Glass DN, Goldenberg J, et al. International League of Associations for Rheumatology classification of juvenile idiopathic arthritis: second revision, Edmonton, 2001. J Rheumatol. 2004;31(2):390-2.

32. Fagerberg UL, Loof L, Myrdal U, Hansson LO, Finkel Y. Colorectal inflammation is well predicted by fecal calprotectin in children with gastrointestinal symptoms. J Pediatr Gastroenterol Nutr. 2005;40(4):450-5.

33. Gracey E, Dumas E, Yerushalmi M, Qaiyum Z, Inman RD, Elewaut D. The ties that bind: skin, gut and spondyloarthritis. Curr Opin Rheumatol. 2019;31(1):62-9.

34. Jacques P, Van Praet L, Carron P, Van den Bosch F, Elewaut D. Pathophysiology and role of the gastrointestinal system in spondyloarthritides. Rheum Dis Clin North Am. 2012;38(3):569-82.

35. Ossum AM, Palm O, Lunder AK, Cvancarova M, Banitalebi H, Negard A, et al. Ankylosing Spondylitis and Axial Spondyloarthritis in Patients With Long-term Inflammatory Bowel Disease: Results From 20 Years of Follow-up in the IBSEN Study. J Crohns Colitis. 2018;12(1):96-104.

36. Chan J, Sari I, Salonen D, Silverberg MS, Haroon N, Inman RD. Prevalence of Sacroiliitis in Inflammatory Bowel Disease Using a Standardized Computed Tomography Scoring System. Arthritis Care Res (Hoboken). 2018;70(5):807-10.

37. Giani T, Bernardini A, Basile M, Di Maurizo M, Perrone A, Renzo S, et al. Usefulness of magnetic resonance enterography in detecting signs of sacroiliitis in young patients with inflammatory bowel disease. Pediatr Rheumatol Online J. 2020;18(1):42.

38. Sudol-Szopinska I, Znajdek M, Gietka P, Vasilevska-Nikodinovska V, Patrovic L, Salapura V. Imaging of juvenile spondyloarthritis. Part II: Ultrasonography and magnetic resonance imaging. J Ultrason. 2017;17(70):176-81.

39. Tibble JA, Sigthorsson G, Foster R, Scott D, Fagerhol MK, Roseth A, et al. High prevalence of NSAID enteropathy as shown by a simple faecal test. Gut. 1999;45(3):362-6.

40. Mari A, Baker FA, Mahamid M, Yacoob A, Sbeit W, Khoury T. Clinical utility of fecal calprotectin: potential applications beyond inflammatory bowel disease for the primary care physician. Ann Gastroenterol. 2019;32(5):425-30.

41. Lamb CA, Kennedy NA, Raine T, Hendy PA, Smith PJ, Limdi JK, et al. British Society of Gastroenterology consensus guidelines on the management of inflammatory bowel disease in adults. Gut. 2019;68(Suppl 3):s1-s106.

\section{Figures}




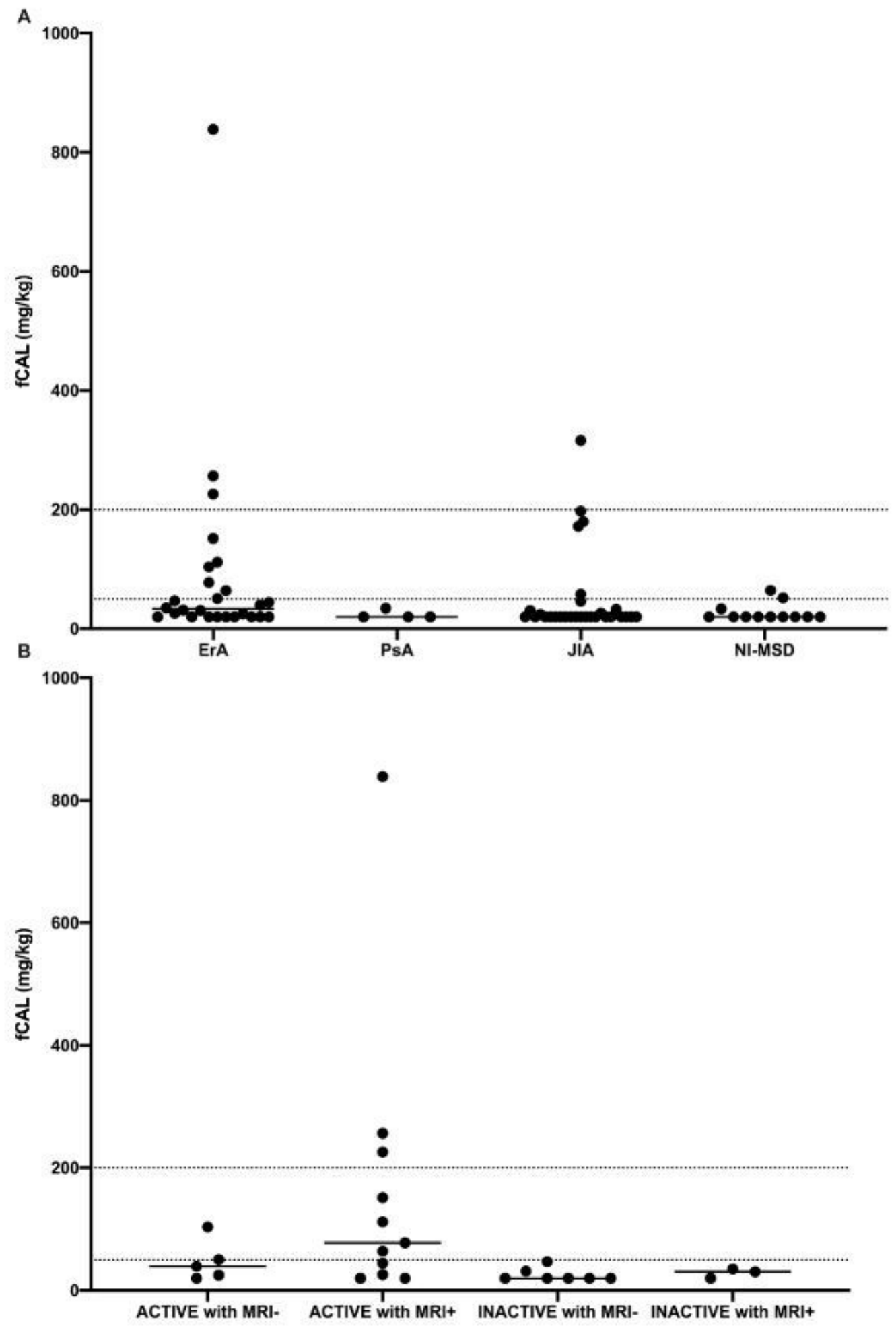

\section{Figure 1}

fCAL concentration in a) juvenile idiopathic arthritis and b) enthesitis related arthritis patients. Each dot represents am fCAL concentration in a single patient, while the horizontal lines represents a median value. There was a significant difference between fCAL concentration among patients with ErA, PsA, JIA and/or NI-MSD ( $p=0.04)$ and between ErA patients with active and/or inactive disease with (MRI+) or without (MRI-) inflammatory changes described by MRI imaging $(p=0.043)$. 
Page 18/18 